\title{
OPTICAL CHARACTERISTICS AND PARAMETERS OF GAS-DISCHARGE PLASMA ON MIXTURES OF MERCURY DICHLORIDE VAPOR AND NEON
}

\author{
A.A. Malinina, R.V. Hrytsak \\ Uzhhorod National University, Uzhhorod, Ukraine \\ E-mail: antonina.malinina@uzhnu.edu.ua
}

The results of studies of the optical characteristics and parameters of DBD (dielectric barrier discharge) plasma on a mixture of mercury dichloride vapor, neon are presented. The following functions were established: EEDF, transport characteristics, specific discharge power losses on electronic processes, electrons' concentration and temperature, rate constants for elastic and inelastic electron scattering on components of the working mixture, depending on the $\mathrm{E} / \mathrm{N}$.

PACS: 42.72.Bj, 52.80.-s, 52.80.Yr

\section{INTRODUCTION}

Gas-discharge plasma on a mixture of mercury dichloride vapor with gases is the working medium of exciplex sources of coherent and spontaneous radiation in the blue-green spectral region with a wavelength at maximum intensity $\left(\lambda_{\max }\right) 557 \mathrm{~nm}[1-12]$. The creation of gas-discharge plasma and the excitation of the components of the working mixture was carried out at atmospheric pressure in volume, glow, barrier and surface discharges. The study of its optical characteristics was carried out in radiators with working volumes $\geq 200 \cdot 10^{-6}$ and $\sim 1 \cdot 10^{-6} \mathrm{~m}^{3}$. Such volumes are necessary to create exciplex radiation sources in the blue-green spectral region with large and small values of the radiation power, and which are used to solve various scientific and applied problems [13]. In spontaneous radiation sources, helium was mainly used as a buffer gas. Their design was coaxial, and the radiating zone was the lateral surface. For a number of scientific and technological applications, it is necessary to provide greater radiation density and its uniformity over the cross section of the emitter and use in the working mixture of more "heavy" buffer gases than helium, which have less penetrating power through the walls of the emitter and thereby providing a longer service life [14].

The aim of the study was to identify regularities in the optical characteristics of a gas-discharge plasma on a mixture of mercury dichloride vapors with neon and to determine the partial pressure of neon at which the maximum radiation power in the blue-green spectral range in the emitter, which design was different from coaxial, is reached. In addition, the purpose of the study was to determine the plasma parameters: the electron energy distribution function, transport and energy characteristics, the fractions of the discharge power on the electronic processes, the concentration and temperature of electrons, and the rate constants of the processes of elastic and inelastic scattering of electrons on the components of the working mixture depending on the value of the reduced electric field $(\mathrm{E} / \mathrm{N}$ is the ratio of the electric field intensity to the total concentration of the components of the working mixture), and also set the value of the parameter $\mathrm{E} / \mathrm{N}$, which ensures the maximum contribution of the discharge power into the radiation in the blue-green spectral region with a wavelength at the maximum intensity $\left(\lambda_{\max }=557 \mathrm{~nm}\right)$.

\section{EXPERIMENTAL INSTALLATION AND METHODS OF EXPERIMENT}

The working mixture in the atmospheric pressure barrier discharge was excited by a power supply with a pulse-periodic output voltage with the possibility of frequency tuning in the range of $1 \ldots 20 \mathrm{kHz}$ and the amplitude of voltage pulses within $10 \ldots 30 \mathrm{kV}$. The research methodology and the research itself were carried out on an experimental setup, which was described in detail in the article [15].

\section{RESEARCH RESULTS AND DISCUSSION}

The emission spectra of gas-discharge plasma were studied in the region of partial pressure of mercury dichloride $0.5 \ldots 2 \mathrm{kPa}$, neon $5 \ldots 140 \mathrm{kPa}$. The voltage, current, and repetition rate of the pump pulses were $20 \ldots 30 \mathrm{kV}, 300 \ldots 325 \mathrm{~A}$, and $10 \ldots 20 \mathrm{kHz}$, respectively.

A characteristic radiation spectrum at a pulse repetition rate of $\mathrm{f}=18 \mathrm{kHz}$ for partial pressures of mercury dichloride and neon 1.5 and $140 \mathrm{kPa}$, respectively, is shown in Fig. 1. Only radiation of the system of electron-vibrational bands of the $\mathrm{B}^{2} \Sigma_{1 / 2}^{+} \rightarrow \mathrm{X}^{2} \Sigma_{1 / 2}^{+}$, $v^{\prime}=0 \ldots 5, v^{\prime \prime}=9 \ldots 19$ transition of exciplex molecules of mercury monochlodide $\left(\mathrm{HgCl}^{*}\right)[10,11]$ is observed with a radiation maximum at a wavelength $\lambda=557 \mathrm{~nm}$, a steep increase in intensity from the long-wavelength region and a slow decline in the short-wave region. The radiation spectra were interpreted using reference data of the work [18].

The band form and its width at half-height $(15 \ldots 16 \mathrm{~nm})$ are similar to the bands corresponding to the $\mathrm{B} \rightarrow \mathrm{X}$ transition of mercury monohalides shown in works in which the creation of a barrier discharge on mixtures of mercury dihalides vapor, helium and other gases was carried out in large sized as well as in smallsized radiators. A sharp increase in the intensity of the radiation in the spectrum was observed from the side of the region with long wavelengths and its slow decrease in the region of shorter wavelengths. The spectra differ in the rate of intensity decrease in the ultraviolet part by the width of the emission band. The radiation spectrum for low partial pressures of neon $(<40 \mathrm{kPa})$ as compared with partial pressures above atmospheric is wider and extends further into the ultraviolet region. 


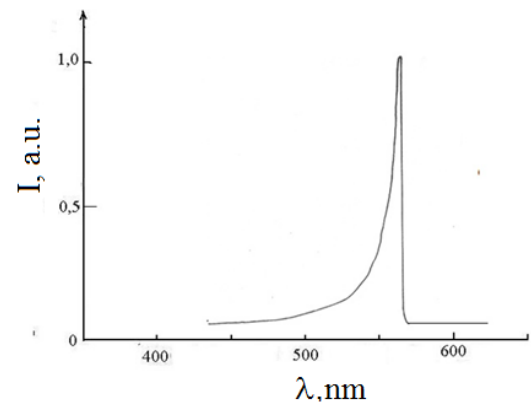

Fig. 1. The emission spectrum of gas-discharge plasma on a mixture of $\mathrm{HgCl}_{2}: \mathrm{Ne}=0.5 \ldots 140 \mathrm{kPa}$

The pump pulse repetition rate is $18 \mathrm{kHz}$

The results of studies of the dependence of the average radiation power on the partial pressures of the neon buffer gas are presented in Fig. 2. An increase in the radiation power is observed with an increase in the neon partial pressure from 28 to $60 \mathrm{~mW} / \mathrm{cm}^{3}$ and with an increase in the neon partial pressure above $110 \mathrm{kPa}$, the power does not change until the neon partial pressure increases to $140 \mathrm{kPa}$.

The results of studies of temporal characteristics of gas-discharge plasma are presented in Fig. 3. Fig. 3,a represent the oscillograms of current pulses of dielectric barrier discharge and radiation, which is shown in Fig. 3,b for the ratio of the components of the mixture, at which the maximum radiation power was reached.

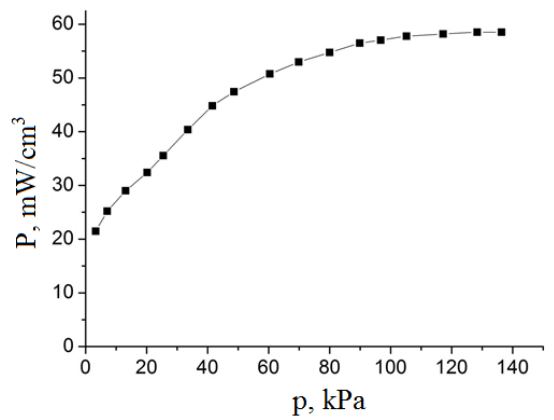

Fig. 2. The dependence of the specific radiation power of a gas-discharge plasma on the partial pressure of neon in the mixture of mercury dichloride vapor and neon. The partial pressure of mercuric dichloride vapor is $1.5 \mathrm{kPa}$. Amplitude of voltage $-30 \mathrm{kV}$. The pulse repetition rate is $18 \mathrm{kHz}$

The maximum values of the amplitude of the current pulse are $325 \mathrm{~A}$. The current pulses are double, of different polarity, the delay between them in our experimental conditions is $150 \mathrm{~ns}$. The leading edge was $10 \mathrm{~ns}$, the duration was $50 \mathrm{~ns}$. The radiation pulses are also double with a time shift relative to each other by $150 \mathrm{~ns}$. Their amplitudes are different in magnitude, the amplitude of the second pulse exceeds the magnitude of the amplitude of the first. The error and reproducibility of the results of oscillographic measurements were 10 and $90 \%$, respectively.

With an increase in the pulse repetition rate, the average radiation power of a gas-discharge plasma increases linearly to frequencies of $20 \mathrm{kHz}$. The nature of the discharge was similar to that typical of a barrier discharge [19]. With an increase in the pump pulse repetition rate, the radiation intensity of a uniform discharge increased, while the intensity of the filament channels fell. The thickness of the discharge region and the burning length of the discharge were 0.005 and $0.20 \mathrm{~m}$, respectively.

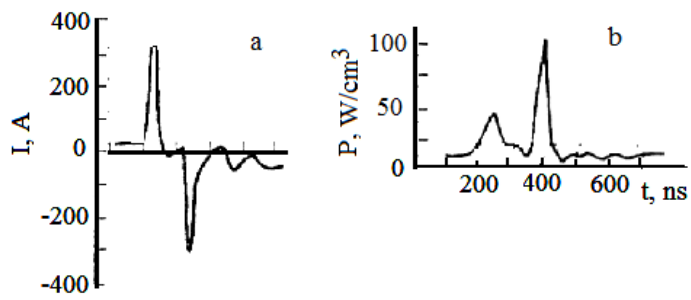

Fig. 3. Oscillograms of discharge current pulses (a) and radiation (b) for the spectral band $\lambda_{\max }=557 \mathrm{~nm}$ spectral band of $\mathrm{HgCl}^{*}$ molecules in a $\mathrm{HgCl}_{2}$ :

Ne mixture. The partial pressure of saturated vapor

$\mathrm{HgCl}_{2}$ is $1.5 \mathrm{kPa}$, the partial pressure of neon is $140 \mathrm{kPa}$. Amplitude of voltage pulses $30 \mathrm{kV}$. Pulse repetition rate is $18 \mathrm{kHz}$

\section{PLASMA PARAMETERS}

Due to the fact that experimental physics does not have satisfactory methods for diagnosing dense gasdischarge plasma, the parameters of the barrierdischarge plasma at optimal for obtaining the maximum radiation power of the $\mathrm{HgCl}_{2}-\mathrm{Ne}$ mixture (0.0107, 0.9893 ) with a total pressure $141.5 \mathrm{kPa}$ were determined numerically and calculated as total integrals of the electron distribution function according to the Boltzmann equation in the two-term approximation [20]. Calculations of the EEDF were performed using the program [21]. Based on the resulting EEDF, mean electron energy, the specific power losses of the electric discharge on various elementary processes in the plasma, and the rate constants of elastic and inelastic scattering of electrons on mercury dichloride molecules and neon atoms are determined depending on the value of the reduced electric field (ratio of electric field ( E) to the total concentration of mercury dichloride molecules and neon atoms $(\mathrm{N}))$. The range of variation of the parameter $\mathrm{E} / \mathrm{N}=$ $1 \ldots 150 \mathrm{Td}\left(1 \cdot 10^{-17} \ldots 15 \cdot 10^{-16} \mathrm{~V} \cdot \mathrm{cm}^{2}\right)$ included the values of the parameter $\mathrm{E} / \mathrm{N}$, which were implemented in the experiment.

All calculations were carried out for a partial pressure of mercury dichloride equal to $1.5 \mathrm{kPa}$, neon $140 \mathrm{kPa}$, at which the maximum value of the radiation power was achieved in the experiment (see Fig. 2). In the electron collision integral with mercury dichloride molecules, nitrogen and neon in the Boltzmann kinetic equation the following processes were taken into account: elastic scattering and excitation of the energy states of the neon atom: elastic scattering, excitation of the energy states of $\mathrm{Ne}$ atom with a threshold energy of $16.62 \mathrm{eV}, 16.67 \mathrm{eV}(1 \mathrm{~s} 4), 16.84 \mathrm{eV}(1 \mathrm{~s} 2), 18.72 \mathrm{eV}$ (2p), $20.0 \mathrm{eV}(2 \mathrm{~s}+3 \mathrm{~d}), 20.65 \mathrm{eV}(3 \mathrm{p}), 4.9 \mathrm{eV}$ and ionization of neon atom, dissociative excitation of the electronic state of mercury monochloride $\left(\mathrm{B}^{2} \Sigma^{+}{ }_{1 / 2}\right)$ and ionization of mercury dichloride molecules. The data on the absolute values of the effective cross sections for these processes, as well as their dependences on the electron energy, are taken from the database [21] and the works [22 - 24].

The concentration of electrons $\left(\mathrm{N}_{\mathrm{e}}\right)$ was calculated by the known formula [25]: 


$$
\mathrm{N}_{\mathrm{e}}=\mathrm{j} / \mathrm{e} \cdot \mathrm{V}_{\text {dr., }}
$$

where $\mathrm{j}$ is the current density in the discharge, e is the electron charge, $\mathrm{V}_{\mathrm{dr}}$ is the electron drift velocity.

The electron drift velocity was determined from the expression [25]:

$$
\mathrm{V}_{\mathrm{dr}}=\mu_{\mathrm{e}} \cdot \mathrm{E},
$$

where $\mu_{\mathrm{e}}$ is the electron mobility, $\mathrm{E}$ is the electric field strength on the plasma.

The electric field strength on plasma $\mathrm{E}$ was calculated by the formula:

$$
\mathrm{E}=\mathrm{U}_{\mathrm{pl}} / \mathrm{d} \text {, }
$$

$\mathrm{U}_{\mathrm{pl}}$ - voltage on the plasma, d-discharge gap.

The voltage on the plasma was determined according to the second Kirchhoff rule using experimentally measured values of the voltage temporal progress applied to the electrodes of the gas-discharge cell $\mathrm{U}$, as well as the voltage drop across the dielectric capacitance $\mathrm{U}_{\text {d. }}[26]$ :

$$
\mathrm{U}_{\mathrm{pl}}=\mathrm{U}_{-}-\mathrm{U}_{\mathrm{dl} .} \text {, }
$$

voltage $\mathrm{U}$ was calculated by the displaced charge $\mathrm{Q}$ and the capacitance of the dielectric barrier $\mathrm{C}_{\mathrm{d}}$ :

$$
\mathrm{C}_{\mathrm{d} .}=\mathrm{Q} / \mathrm{C}_{\mathrm{d} .} \text {. }
$$

The charge transferred in the circuit was determined by integrating the current, taking into account the initial conditions:

$$
\mathrm{Q}(\mathrm{t})=\int_{0}^{t} I(t) d t+\mathrm{Q}_{0},
$$

where $\mathrm{Q}_{0}=\mathrm{Q}(\mathrm{t}=0)$.

As a result, the electric field strength at the plasma gap for a mixture of mercury dichloride and neon was $2.2 \times 10^{6} \mathrm{~V} / \mathrm{m}$, and the reduced electric field $(\mathrm{E} / \mathrm{N})=$ $100 \mathrm{Td}$ for the total concentration of the components of the mixture $(\mathrm{N})=2.2 \times 10^{25} \mathrm{~m}^{-3}$, at which the maximum radiation power in the spectral band $\left(\lambda_{\max }=557 \mathrm{~nm}\right)$ of mercury monochloride molecules was observed in the experiment.

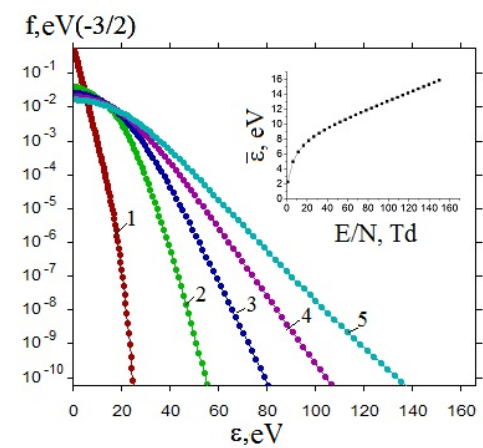

Fig. 4. The electron energy distribution functions in the discharge for the mixture: $\mathrm{HgCl}_{2}-\mathrm{Ne}$ (0.0107, 0.9893)

at a total mixture pressure $141.5 \mathrm{kPa}$ for the values of the parameter $E / N$ : 1 (1), 38.2 (2), 75.5 (3),

113.3 (4), 150 (5) Td; the inset shows the dependence of mean electron energy on the parameter $E / N$

Mean energy of plasma electrons in a mixture of $\mathrm{HgCl}_{2}-\mathrm{Ne}$ most depend on the parameter $\mathrm{E} / \mathrm{N}$ in the range $1 \ldots 17 \mathrm{Td}$ (Fig. 4, insert). At the same time, it linearly increases from 2.3 to $7.2 \mathrm{eV}$. In the range of values of the parameter $\mathrm{E} / \mathrm{N}=17 \ldots 150 \mathrm{Td}$, mean electron energy is also increased from 7.2 to $15.9 \mathrm{eV}$, but at a lower rate. The slower increase in mean electron energy in this range of the $\mathrm{E} / \mathrm{N}$ parameter is associated with the losses of the energy of fast electrons on the excitation of the energetic states of mercury dichloride molecules and neon atoms. For the values of the reduced electric field at which the experimental studies were performed $(100 \mathrm{Td})$, mean electron energy was $13.1 \mathrm{eV}$, the electron drift velocity $2.4 \times 10^{5} \mathrm{~m} / \mathrm{s}$, the electron concentration $9.8 \times 10^{15} \mathrm{~m}^{-3}$.

The distribution of the specific loss of discharge power on the dissociative excitation of $\mathrm{B}^{2} \Sigma^{+}{ }_{1 / 2}$-state of mercury monohloride molecules by electrons in the change of the reduced electric field intensity in the range $\mathrm{E} / \mathrm{N}=(1 \ldots 150) \mathrm{Td}$ is shown in Fig. 5.

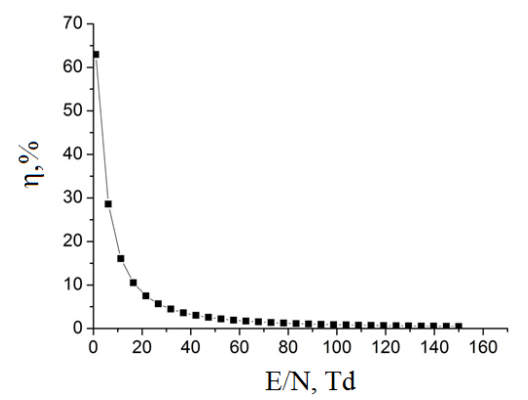

Fig. 5. The dependence of specific losses of discharge power on dissociative excitation by electrons of $B^{2} \Sigma^{+}{ }_{1 / 2-}^{-}$ state of mercury monochloride molecule in plasma on $\mathrm{HgCl}_{2}$-Ne mixtures $(0.0107,0.9893)$ with total pressure of $141.5 \mathrm{kPa}$

For the dissociative excitation process of $\mathrm{B}^{2} \Sigma^{+}{ }_{1 / 2}^{-}$ state of mercury monohloride molecules by electrons, the specific loss of power of the discharge decreases with the increase of the parameter E/N. It reaches a maximum of $63 \%$ at $\mathrm{E} / \mathrm{N}=1 \mathrm{Td}$. The rate of reduction of the loss of specific power of discharge for this process and its magnitude are related to the nature of the dependence of the effective cross section of the energy state on the energy of the electrons and its absolute value, the dependence of the EEDF on the value of the reduced electric field and the energy of the dissociative excitation threshold of mercury monohloride molecules. For the dissociative excitation process of $\mathrm{B}^{2} \Sigma^{+}{ }_{1 / 2}$-state of mercury monochloride by electrons, the specific loss of discharge power is $0.9 \%$ for the reduced electric field $\mathrm{E} / \mathrm{N}=100 \mathrm{Td}$ (at which experimental studies were conducted).

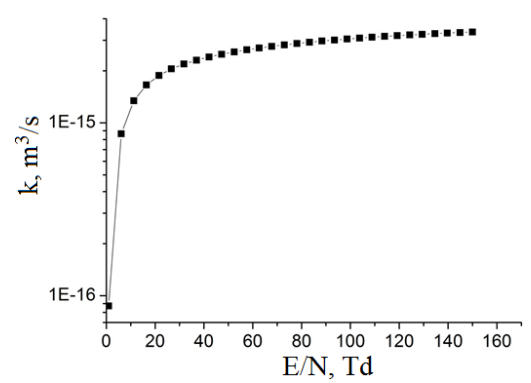

Fig. 6. The dependence of the rate constant of the dissociative excitation of the $B^{2} \Sigma_{1 / 2}^{+}$-state of a mercury monochloride molecule by electrons on the parameter $E / N$ in a discharge in a mixture: $\mathrm{HgCl}_{2}-\mathrm{Ne}$ (0.0107, 0.9893) at a total pressure of $141.5 \mathrm{kPa}$

Fig. 6 shows the results of a numerical calculation of the rate constant for the process of dissociative excitation by electrons of the $\mathrm{B}^{2} \Sigma^{+}{ }_{1 / 2}$-state of mercury mono- 
chloride molecules by electrons. It is observed the increase in it with an increase in the reduced electric field. The rate constant of dissociative excitation by electrons of the $\mathrm{B}^{2} \Sigma_{1 / 2}^{+}$-state of mercury monochloride is equal to $3.1 \cdot 10^{-15} \mathrm{~m}^{3} / \mathrm{s}$ for a reduced electric field $\mathrm{E} / \mathrm{N}=100 \mathrm{Td}$. The emission of spectral bands with a maximum at the wavelength $\lambda=557 \mathrm{~nm}$ of the electron-vibrational transition $\mathrm{B}^{2} \Sigma_{1 / 2}^{+} \rightarrow \mathrm{X}^{2} \Sigma_{1 / 2}^{+}$of $\mathrm{HgCl}^{*}$ molecules in a gasdischarge plasma on mixtures of mercury dichloride with neon occurs as a result of the processes leading to formation and destruction of the $\mathrm{B}^{2} \Sigma_{1 / 2}^{+}$-state of mercury monochloride, the main of which are [22 - 24]:

$$
\begin{aligned}
& \mathrm{HgCl}_{2}+\mathrm{e} \rightarrow \mathrm{HgCl}_{2}\left({ }^{3,1} \Sigma_{\mathrm{u}}^{+}\right) \rightarrow \mathrm{Cl}+\mathrm{e} \\
& \rightarrow \operatorname{HgCl}\left(B^{2} \Sigma_{1 / 2}^{+}\right)+ \\
& \mathrm{HgCl}\left(B^{2} \Sigma_{1 / 2}^{+}\right) \rightarrow \operatorname{HgCl}\left(X^{-} \Sigma_{1 / 2}^{+}\right)+\mathrm{hv}, \\
& \lambda_{\max }=557 \mathrm{~nm}
\end{aligned}
$$$$
\operatorname{HgCl}\left(B^{2} \Sigma_{1 / 2}^{+}\right)+\mathrm{M} \rightarrow \operatorname{HgCl}\left(X^{2} \Sigma_{1 / 2}^{+}\right)+\mathrm{M}+\Delta \mathrm{E},
$$

where $\mathrm{M}$ - concentrations of molecules $\mathrm{HgCl}_{2}, \mathrm{Ne} ; \Delta \mathrm{E}$ - the difference of energy in the reaction.

Reactions (1) and (2) are the main sources of formation of exciplex molecules $\mathrm{HgCl}^{*}[22,23]$. Electronvibrational transitions $B^{2} \Sigma_{1 / 2}^{+} \rightarrow X^{2} \Sigma_{1 / 2}^{+}$of $\mathrm{HgCl}^{*}$ molecules lead to the emission of spectral bands with maximum intensity at wavelength $\lambda_{\max }=557 \mathrm{~nm}$ (reaction (3)). In the quenching reaction (4) there is an electron-vibrational transition of mercury monohloride molecules to the ground state without radiation [24].

In addition to processes (1)-(4), which lead to the formation and destruction of the $\mathrm{B}^{2} \Sigma_{1 / 2}^{+}$-state of mercury monochloride, next processes are also possible:

$$
\begin{aligned}
& \mathrm{HgCl}_{2}+\mathrm{e} \rightarrow \mathrm{HgCl}_{2}(\mathrm{D}) \rightarrow \operatorname{HgCl}\left(C^{2} \Pi_{1 / 2}, D^{2} \Pi_{3 / 2}\right)+ \\
& \quad+\mathrm{Cl}+\mathrm{e}, \\
& \mathrm{HgCl}\left(C^{2} \Pi_{1 / 2}, D^{2} \Pi_{3 / 2}\right)+\mathrm{HgCl}_{2}(\mathrm{Ne}) \rightarrow \\
& \quad \rightarrow \operatorname{HgCl}\left(B^{2} \Sigma_{1 / 2}^{+}\right)+\mathrm{M}+\Delta \mathrm{E}_{1,2},
\end{aligned}
$$

in addition to processes (1) and (2), a non-radiation emitting process is possible:

$$
\mathrm{HgCl}_{2}+\mathrm{e} \rightarrow \mathrm{HgCl}_{2}\left({ }^{3,1} \Sigma_{\mathrm{u}}^{+}\right) \rightarrow \operatorname{HgCl}\left(X^{2} \Sigma_{1 / 2}^{+}\right)+\mathrm{Cl}+\text { e. (7) }
$$

Process (5) is the process of excitation of $\mathrm{HgCl}_{2}$ molecules by electrons to the state $\mathrm{D}[27,28]$. This state of mercury dichloride molecules is the sum of all states that are located between the threshold energy $(7 \mathrm{eV})$ and the ionization energy $(11.4 \mathrm{eV})$ [27]. It can be expected that the effective cross section for the excitation of this state by electrons for mercury dichloride molecules is close to the effective excitation cross section $\mathrm{D}$ of the state of mercury dibromide molecules, the value of which is $10^{-15} \mathrm{~cm}^{2}$ [28].

Emission from the $\mathrm{D}$ states of the $\mathrm{HgCl}_{2}$ molecules is not observed, due to the fact that this state dissosiates with the formation of mercury monochloride molecules in $(\mathrm{C}, \mathrm{D})$ states. The emission of $\mathrm{HgCl}^{*}$ molecules with $\mathrm{C}$ and $\mathrm{D}$ states under our experimental conditions is not observed due to the high efficiency of the quenching process (6). The population of these states is transferred to $B^{2} \Sigma_{1 / 2}^{+}$-state of $\mathrm{HgCl}$ molecules or to other nonoptical channels $[6,28]$. The reaction of the collision of mercury dichloride molecules with electrons (7) is the channel for the formation of mercury monochloride molecules in the ground state, the rate constant of which is $8 \times 10^{-15} \mathrm{~m}^{3} / \mathrm{s}$ [29].

The sharp increase in intensity from the part of the spectrum with long wavelengths and its slow decrease in the region of short wavelengths (see Fig. 1) is explained by the course of potential curves (excited $\mathrm{B}^{2} \Sigma^{+}{ }_{1 / 2}$-state is shifted towards large internuclear distances of relative $\mathrm{X}^{2} \Sigma^{+}{ }_{1 / 2}$-state) and processes of relaxation of the population of the upper vibrational levels of the excited electronic state, which occur faster than the electronic-vibrational transition to the ground $X^{2} \Sigma^{+}{ }_{1 / 2}^{-}$ state $[30,31]$.

The oscillatory structure of the current pulse (see Fig. 3,a) is caused by charging and discharging the dielectric capacitance during a voltage pulse with an amplitude sufficient to break the discharge gap [19]. The difference in the shape of current pulses at the front and back fronts is associated with opposite directions of current flow through the gas-discharge gap $\left(1.4 \times 10^{-2} \mathrm{~m}\right)$ and, as a result, unequal charge resorption conditions on the inner surface of the dielectric under conditions equal to the barrier discharge used in our experiment.

The regularity of the difference in the amplitudes of the first and second radiation pulses (see Fig. 3,b) is explained as follows. The first and second pump pulses (current) form mercury monochloride molecules in $\mathrm{B}^{2} \Sigma^{+}{ }_{1 / 2^{-}}$and $\mathrm{X}^{2} \Sigma^{+}{ }_{1 / 2}$-states due to dissociation of mercury dichloride molecules when colliding with electrons. The second pump pulse (current), in addition, leads to an additional increase in the population of $\mathrm{B}^{2} \Sigma^{+}{ }_{1 / 2}$ state of mercury monochloride molecules due to the process:

$$
\mathrm{e}+\mathrm{HgCl}\left(\mathrm{X}^{2} \Sigma_{1 / 2}^{+}\right) \rightarrow \mathrm{e}+\mathrm{HgCl}\left(\mathrm{B}^{2} \Sigma_{1 / 2}^{+}\right),
$$

where $\mathrm{HgCl}\left(\mathrm{X}^{2} \Sigma^{+}{ }_{1 / 2}\right)$ mercury monochloride molecules in the ground state, and which did not have time to recover in a triatomic molecule (mercury dichloride) in the interpulse period (150 ns) in the process $[29,32]$ :

$$
\mathrm{HgCl}\left(\mathrm{X}^{2} \Sigma_{1 / 2}^{+}\right)+\mathrm{Cl}+\mathrm{N}_{2} \rightarrow \mathrm{HgCl}_{2}+\mathrm{N}_{2} \text {. }
$$

\section{CONCLUSIONS}

The design of the gas-discharge radiation source provided a diffuse and uniform discharge pattern, the cross section of which was $(5 \times 14) \cdot 10^{-6} \cdot \mathrm{m}^{2}$, and its length was $0.2 \mathrm{~m}$.

The gas-discharge plasma of a barrier discharge on a mixture of mercury dichloride and neon vapor produces the emission of the spectral band of an exciplex molecule mercury monochloride in the blue-green spectral region $\left(\lambda_{\max }=557 \mathrm{~nm}\right)$.

The following functions were established: electron energy distribution functions, transport characteristics, specific discharge power losses on electronic processes, as well as processes rate constants: elastic and inelastic scattering of electrons on the working mixture components depending on the magnitude of the reduced electric field.

For values of the reduced electric field at which experimental studies were carried out $(100 \mathrm{Td})$, mean electron energy was $13.1 \mathrm{eV}$, which corresponded to the electron temperature of $151960 \mathrm{~K}$, the electron drift velocity was $2.4 \times 10^{5} \mathrm{~m} / \mathrm{s}$, and the electron concentra- 
tion was $9.8 \times 10^{15} \mathrm{~m}^{-3}$. The portion of the discharge power going into the process of dissociative excitation by electrons of molecules of mercury monochloride reached a maximum of $0.9 \%$, with the values of the $\mathrm{E} / \mathrm{N}$ parameter equal to $100 \mathrm{Td}$ for the electronic state $\mathrm{B}^{2} \Sigma_{1 / 2}^{+}$. The rate constant of the process leading to the formation of mercury monochloride molecules is $3.1 \times 10^{-15} \mathrm{~m}^{3} / \mathrm{s}$ for a reduced electric field $(\mathrm{E} / \mathrm{N})=$ $100 \mathrm{Td}$, at which experimental studies were carried out.

To achieve high values of the radiation power of gas-discharge plasma on a mixture of mercury dichloride vapor and neon in the blue-green spectral region $\left(\lambda_{\max }=557 \mathrm{~nm}\right)$, it is necessary to reduce the value of the reduced electric field strength to $1 \mathrm{Td}$, at which the portion of power input is maximal.

The gas-discharge source of radiation of the bluegreen spectral range, the working medium of which was the plasma of a barrier discharge on a mixture of mercury dichloride vapor and neon, can be used in scientific research in the field of biotechnology, photonics, medicine, as well as to create indicator gas-discharge panels.

\section{ACKNOWLEDGMENT}

The authors of the article are grateful to prof. A.N. Malinin for assistance in the discussion of research results.

\section{REFERENCES}

1. J.H. Parks. Collisional quenching kinetics for the $\mathrm{HgCl}^{*}\left(\mathrm{~B}^{2} \Sigma_{1 / 2}^{+}\right)$state // Appl. Phys. Lett. 1977, p. 297.

2. R. Burnliam. Discharge pumped mercuric halide dissociation lasers //Appl. Phys. Lett. 1978, № 2, p. 152-156.

3. I.S. Lakoba, S.I. Yakovlenko. Active media of exciplex lasers (review) // Soviet Journal of Quantum Electronics. 1980, № 4, p. 677-719.

4. R. Burnham, E.J. Schimitschek. High power bluegreen lasers // Laser Focus. 1981, № 6, p. 54-61.

5. S.P. Bazhulin, N.G. Basov, S.N. Bugrimov, V.S. Zuev, A.S. Kamrukov, G.N. Kashnikov, N.P. Kozlov, P.A. Ovchinnikov, A.G. Opekan, V.K. Orlov, Yu.S. Protasov. Green-emitting mercury chloride laser pumped by wide-band optical radiation // Soviet Journal of Quantum Electronics. 1986, № 6, p. 12751278.

6. A.M. Boychenko, M.I. Lomaev, A.N. Panchenko, et al. Ultraviolet and Vacuum-Ultraviolet Excilamps: Physics, Technique and Application. Tomsk: «STT», 2011, p. 512.

7. A.N. Malinin. Excitation of mercury monohalides in the plasma of pulse-periodic discharge in mixtures of mercury dihalides and rare gases // Laser Physics. 1997, № 5, p. 1032-1040.

8. A.N. Malinin. The Main Characteristics of the Plasma of Pulse Glow Discharge in Mixtures of Mercury Dihalide and Rare Gases // Laser Physics. 1998, № 2, p. 395-406.

9. M.M. Guivan, O.M. Malinin, L.L. Shimon. Optimization of component compound of the gas-discharge $\mathrm{HgBr}$-excimer lamp // Scientific Bulletin of Uzhgorod National University. Series Physics. 1999, p. 1217.
10. A.N. Malinin, M.M. Guivan, L.L. Shimon. Emission spectra of working mixtures of a $\mathrm{HgBr} / \mathrm{HgCl}$ excimer lamp // Optics and spectroscopy. 2000, № 6, p. 829-833.

11. M.M. Guivan, O.M. Malinin, L.L. Shimon. Optimization of optical characteristics of working mixtures of $\mathrm{HgBr}$ and $\mathrm{HgCl}$ excilamps // Journal of Physical Research. 2002, № 1, p. 74-77.

12. M.M. Guivan, O.M. Malinin. Investigation of the excitation excitatory molecule of monobromide and mercury monohloride in a dense gas-discharge plasma // Ukrainian Journal of Physics. 2002, p. 24-27.

13. V.D. Romanenko. Biotechnology of the cultivation of hydrobionts. Kiev, 1999, p. 264.

14. U. Kogelschatz. Fundamentals and Applications of Dielectric-barrier Discharges. ABB Corparate Research Ltd, 5405 Dfden, Switzerland. 2000, p. 1-7.

15. A.A. Malinina, A.N. Malinin. Optical characteristics and parameters of gas-discharge plasma in a mixture of mercury dibromide vapor with neon. 2013, № 12, p. 1035-1042.

16. A.E. Efimov, L.P. Belorukova, I.V. Vasilkova, V.P. Chechev. Properties of inorganic compounds. Reference book. L.: "Chemistry", 1983, p. 383.

17. R.A. Sapozhnikov. Theoretical photometry. M.: "Energia", 1977, p. 264

18. R.W. Pears, A.G. Gaydon. The Identification of Molecular Spectra. London: Chopman Holl LT, 1963, p. 347.

19. Yu. S. Akishev, A.V. Demyanov, V.B. Karalnik, et al. Pulsed regime of the diffusive mode of a barrier discharge in helium // Plasma Physics Reports. 2001, № 2, p. 164-171.

20. G.J.M. Hagelaar, L.C. Pitchford. Solving the Boltzmann equation to obtain electron transport coefficients and rate coefficients for fluid models // Plasma Sources Sci Technol. 2005, p. 722-733.

21. http://www.siglo-kinema.com/.

22. V. Kushawaha, M. Mahmood. Electron impact dissociation of $\mathrm{HgX}_{2}(\mathrm{X}=\mathrm{Cl}, \mathrm{Br}, \mathrm{I}) / / \mathrm{J}$. Appl. Phys. 1987, p. 2173.

23. A.N. Malinin. Excitation of the $\mathrm{B}^{2} \Sigma^{+}{ }_{1 / 2}$-state of mercury monohalides by electron impact // Laser Physics. 1997, № 6, p. 1168-1176.

24. A. Mandl, J.J Parks, C. Roxlo. Collisional quenching kinetics for the $\mathrm{HgCl}$ and $\mathrm{HgBr}\left(\mathrm{B}^{2} \Sigma^{+}{ }_{1 / 2}\right)$ state // J. Chem. Phys. 1980, № 1, p. 504-507.

25. Yu.P. Raizer. Gas Discharge Physics. Berlin: Springer, 1991, p. 450.

26. M.I. Lomaev, V.S. Skakun, E.A. Sosnin, et al. Excilamps: efficient sources of spontaneous UV and VUV radiation // Physics Uspekh. 2003, p. 201-217.

27. W.R. Wadt. The electronic structure of $\mathrm{HgCl}_{2}$ and $\mathrm{HgBr}_{2}$ and its relationship to photodissociation // J. Chem. Phys. 1980, p. 2469-2478.

28. W.L. Nighan, R.T. Brown. Kinetic processes in the $\mathrm{HgBr}(\mathrm{B} \rightarrow \mathrm{X}) / \mathrm{HgBr}_{2}$ dissociation laser // J. Appl. Phys. 1982, p. 7201-7210.

29. V.V. Datsyuk, I.A. Izmailov, V.V. Naumov, V.A. Kochelap. Direct electron-impact mechanism of excitation of mercury monobromide in a doublepulse dielectric-barrier-discharge $\mathrm{HgBr}$ lamp // Plasma Sources Sci. Technol. 2016, p. 045020. 
30. W.R. Wadt. The electronic structure of $\mathrm{HgCl}$ and HgBr // Appl. Phys. Lett. 1979, p. 658.

31. V.V. Datsyuk, I.A. Izmailov, V.A. Kochelap. Oscillatory relaxation of excimer molecules // Physics Uspekh. 1998, p. 439-464.
32. A.C. Erlandson, T.A. Cool. On the regeneration mechanism of $\mathrm{HgBr}$ in $\mathrm{HgBr} / \mathrm{HgBr}$ dissociation lasers // Chem. Phys. Lett. 1983, p. 685-689.

Article received 29.05.2019

\section{ОПТИЧЕСКИЕ ХАРАКТЕРИСТИКИ И ПАРАМЕТРЫ ГАЗОРАЗРЯДНОЙ ПЛАЗМЫ НА СМЕСЯХ ПАРОВ ДИХЛОРИДА РТУТИ И НЕОНА}

\section{А.А. Малинина, Р.В. Грицак}

Представлены результаты исследований оптических характеристик и параметров газоразрядной плазмы барьерного разряда на смеси паров дихлорида ртути и неона. Установлены: ФРЭЭ, транспортные характеристики, удельные потери мощности разряда на электронные процессы, концентрация и температура электронов, константы скоростей процессов упругого и неупругого рассеяния электронов на компонентах рабочей смеси в зависимости от величины приведенной напряженности электрического поля.

\section{ОПТИЧНІ ХАРАКТЕРИСТИКИ І ПАРАМЕТРИ ГАЗОРОЗРЯДНОЇ ПЛАЗМИ НА СУМІШАХ ПАРІВ ДИХЛОРИДУ РТУТІ І НЕОНУ}

\section{А.О. Малініна, Р.В. Грицак}

Представлено результати досліджень оптичних характеристик і параметрів газорозрядної плазми бар'єрного розряду на суміші парів дихлориду ртуті і неону. Встановлено: ФРЕЕ, транспортні характеристики, питомі втрати потужності розряду на електронні процеси, концентрація і температура електронів, константи швидкостей процесів пружного і непружного розсіювання електронів на компонентах робочої суміші в залежності від величини приведеної напруженості електричного поля. 